\title{
土木类专业人才沟通能力培养体系的研究与实践
}

蒋玉飞 ${ }^{1}$ 刘杞威 ${ }^{2}$ 李 倩 $^{3}$

1.四川大学锦江学院 2. 中建五局三公司四川分公司 3. 四川大学锦江学院

DOI:10.32629/mef.v1i1.12

[摘 要] 随着建筑人才市场对专业从业人员技术交流能力要求的不提高, 高校对土木类专业学生沟通能力的培养也日 益关注。文章通过四川大学锦江学院多年来在土木类专业学生沟通能力培养中的研究与实践, 对土木类专业学生沟通能 力培养体系和培养路径进行了论述。

[关键词] 土木类专业人才; 沟通能力; 培养体系; 培养路径

近四年, 四川大学锦江学院对招聘了我校较多土木类 专业应届毕业生的45家企业进行了走访和调研, $89 \%$ 的企 业认为目前应届毕业生的沟通能力为最为欠缺的能力之 一, 特别是技术交流能力亟待提高, 因此土木类专业人才 沟通能力的培养意义重大。通过多年的探索, 我院在“土 木类专业人才沟通能力培养体系”的建立过程中进行了如
下研究与实践。

1 构建了土木类专业沟通能力培养框架体系

针对当前企业对人才沟通能力的需求, 提出了“沟通+ 技能”型人才培养的理念, 将沟通能力的培养融人到了专 业知识的教育体系中, 构建了渗透本科教学全过程的系列 化、多层次、全方位的沟通能力培养体系, 如图1所示。

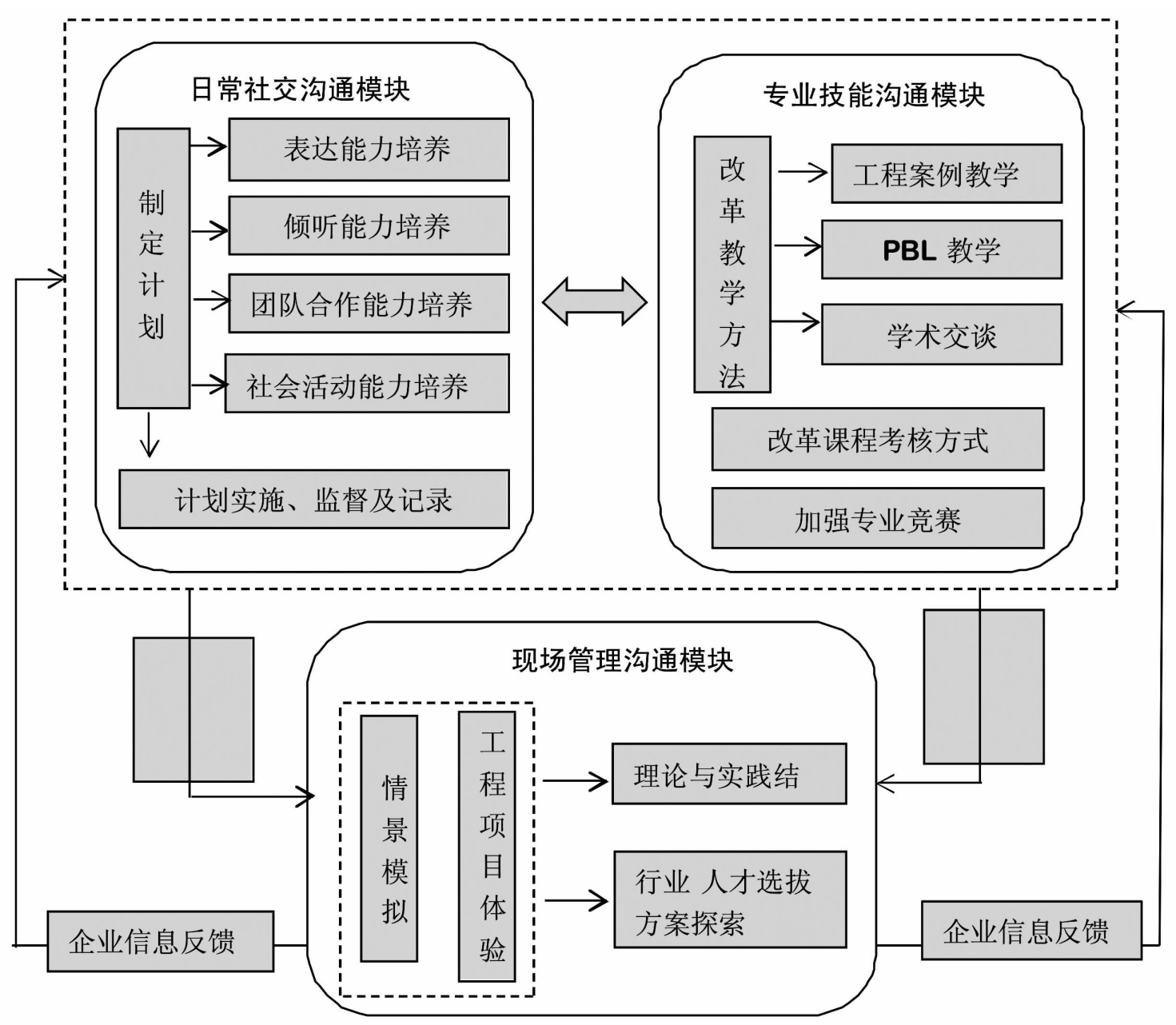

图1 土木类专业人才沟通能力培养体系图 
上图中, 日常社交沟通为基础模块、专业技能沟通作 为提升模块、现场管理沟通模块作为反映学生综合素质 的检验模块。三个模块既有各自的侧重点, 又相辅相成, 该体系将沟通能力培养贯穿于本科教学的全过程, 有效 地提高了学生的综合素质。

\section{2 制定了土木类专业沟通能力培养路径}

为了满足我国对未来工程建设复合型人才的重要需 求, 响应 “沟通>技能” 的教育口号, 提出了解决现有教学 问题的手段与措施。培养学生沟通交流能力需全面、均衡,
我院采用三模块法实现沟通能力培养的目标。

\section{1 日常社交模块}

日常人际交流沟通能力是一项很重要的综合素质, 大多数人认同它的重要性, 但并不重视它的重要性。在高 校教育中, 往往仅仅把它放在学生活动中任学生自由发 挥, 并没有引起足够重视。针对此种现象, 本专业以土木工 程学院学生活动为载体, 在社会调研、文体活动、志愿者服 务、暑期社会实践四方面强化了学生日常社交能力的培 养,学生活动如表1所示.

表 1 日常社交能力学生活动表

\begin{tabular}{|c|c|c|}
\hline 项目 & 活 动类 型 & 活 动 内容 \\
\hline \multirow{3}{*}{ 社会调研 } & 二胎房前景 & 前期准备、调研、分析 \\
\hline & 留守儿童教育 & 前期准备、调研、分析 \\
\hline & 大学生创业 & 前期准备、调研、分析 \\
\hline \multirow{3}{*}{ 文体活动 } & 文艺表演 & 迎新晚会、新年晚会 \\
\hline & 团体比赛 & 拔河比赛、合唱比赛、足球赛 \\
\hline & 个人比赛 & 街舞大赛、歌手大赛 \\
\hline \multirow{3}{*}{ 志愿者服务 } & 一周一支教 & 志愿者教师 \\
\hline & 定期主题活动 & 义诊、义卖 \\
\hline & 特色志愿者帮扶活动 & 关爱孤寡老人、特殊群体 \\
\hline \multirow{2}{*}{ 暑期社会实践 } & “三下乡”活动 & 修葺小学乒乓球台、美化小学墙面 \\
\hline & “快乐学校” & 关爱暑期留守儿童 \\
\hline
\end{tabular}

2.2 专业技能沟通模块

当代土木工程类教育教学, 教师将教学的重点放在 技术教学、知识教授这两个层面上, 重教授而轻表达; 学生 忙于应付各种考试, 重写而轻说。针对此现象, 本成果通过 以下途径进行改进。

\subsection{1专业教学方法改革}

本专业在部分专业课程 (如《建设法规》、《钢筋混凝 土与砌体结构设计》) 中采用多元化教学方法, 如情景模拟 教学、PBL教学、翻转课堂教学等。《建设法规》课程中“开 标现场”情景模拟的应用过程如图2所示。

通过情景模拟、角色扮演、小组讨论 (小组内部讨论、 小组之间讨论) 等教学活动, 激发学生参与的兴趣, 调动师 生互动、学生与学生互动的积极性, 从而增强学生的专业 技能沟通能力。

\subsection{2 构建学生沟通能力的综合考评机制}

对传统考核方式进行改革, 从只有“写”到“写+说”相 结合进行综合考评。《建筑与装饰装修工程计量与计价课 程设计》及《工程算量软件应用》等实践课程考核, 由原有 单一的作品设计考核, 改革为“作品设计”+“答辩”的考核

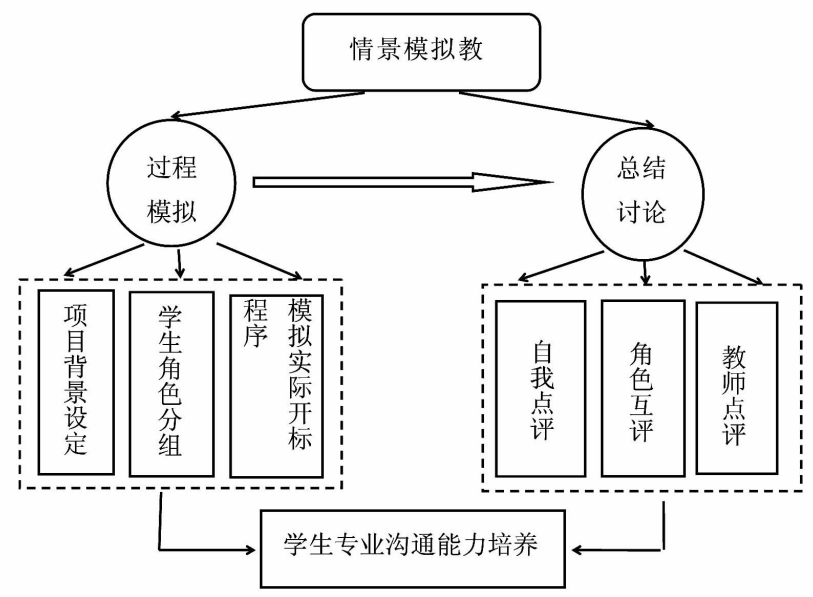

图2 情景模拟教学思路设计图

模式; 《建设工程成本管理》、《建筑平法识图与钢筋算量》 等理论课程在平时成绩中增加“课堂表现”项, “课堂表现” 占平时成绩的 $30 \%$, 以后逐步推广到 $50 \%$ 。

《工程算量软件应用》课程中学生的答辩环节简介如 图3所示: 


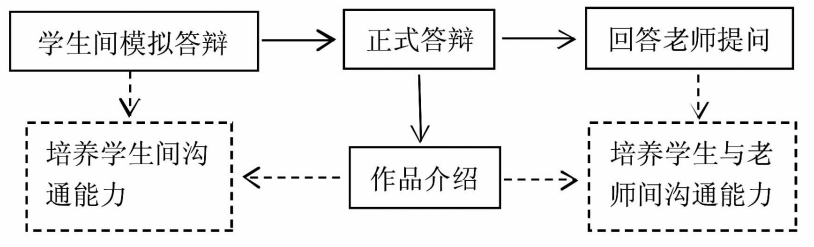

图3 课程答辩设计图

2.2.3 鼓励参加专业竞赛, 提升专业沟通能力

工程造价专业竞赛题目主要源于实际工程, 既能拓 展学生的工程视野又能引发学生的热烈兴趣。专业竞赛 具有鲜明的主体性、协助性和互动性, 它使学生与老师之 间、学生与学生之间的学习互动成为必要和可能。竞赛的 每件作品几乎都是团队合作的产物, 对培养学生专业沟通 能力有极大的帮助。

\section{3 工程管理沟通模块}

工程管理沟通能力的培养主要依托于已有的校企合 作平台, 工程工作性质的复杂性使得行业企业对于人才 的沟通交流能力十分看重。为了践行和强化前期两个模 块的培养成果, 借助校企合作平台让学生在实际工程环 境中进一步得到工程管理沟通交流能力的锻炼, 最终实现 毕业生更好、更快的到岗工作, 缩短融人时间, 减少企业人 才培养成本。具体采取的措施如下:

\subsection{1 情景模拟}

情景模拟的思路来源于模拟法庭, 为了实现系统的 锻炼, 设定一系列与工程相关的虚拟环节, 让学生体验如 真实版的工程管理问题考验。整个过程如图4所示。

\subsection{2 实际工程项目体验}

情景模拟采用预设环节实现全面、系统的沟通能力 培养, 而实际工程体验则极具未知性、灵活性。为了能让 学生在真实的工程中体验沟通交流技巧, 实现虚实转换, 达到能随机应变的驾驭各种工程交流技巧，基于已有的 校企合作平台, 部分学生将被送到企业的实际工程中参 与工程项目的运作, 我院基于的校企合作平台包括了设
计、施工、监理、工程咨询等企业类型, 可依据学生能力培 养的具体需要择优制定工程项目体验计划。

\section{3 结论}

通过以上土木类专业沟通能力培养体系及培养路径 的实践, 土木类应用型人才的沟通能力 (特别是专业技术

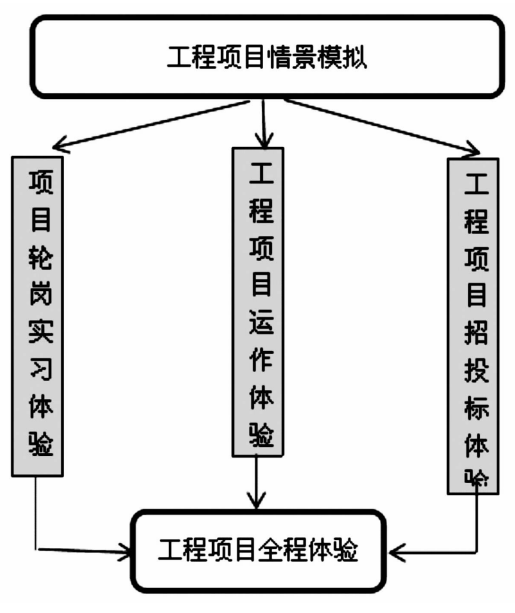

图4 情景模拟框架图

沟通能力)得到了较好的训练和发展, 有助于毕业生更快 的适应建设领域相关的工作岗位。

\section{[参考文献]}

[1] 刘中艳. 高校工商管理专业大学生人际沟通能力 培养研究 [J].兰州教育学院学报,2017,(8).156-158.

[2] 郑雅心. 浅谈项目管理中的沟通艺术及现实启示 [J].西部皮革,2018,(16).140.

作者简介: 蒋玉飞(1986.01-), 女, 汉族, 湖北当阳市人, 硕 士,讲师,研究方向:工程管理。

基金项目: 本文系四川大学锦江学院2017一2020年人才培 养质量和教学改革项目 “校企合作模式下提升应用型人才 毕业实践培养效果的改革与探讨”(编号:JG201707)。 